\title{
Cyanuric Chloride as an Efficient Catalyst for the Synthesis of 2,3-Unsaturated $O$-Glycosides by Ferrier Rearrangement
}

\author{
Xiaojuan Yang ${ }^{1}$ and $\mathrm{Na} \mathrm{Li}^{2}$ \\ ${ }^{1}$ College of Chemistry and Chemical Engineering, Xinxiang University, Xinxiang, Henan 453003, China \\ ${ }^{2}$ School of Pharmacy, Xinxiang Medical University, Xinxiang, Henan 453003, China \\ Correspondence should be addressed to Xiaojuan Yang; yangxiaojuan2005@126.com
}

Received 19 August 2013; Accepted 20 October 2013; Published 19 January 2014

Academic Editors: H. Miyabe, H. Pellissier, and I. Shibata

Copyright (c) 2014 X. Yang and N. Li. This is an open access article distributed under the Creative Commons Attribution License, which permits unrestricted use, distribution, and reproduction in any medium, provided the original work is properly cited.

Cyanuric chloride has been found to be an efficient catalyst for the synthesis of 2,3-unsaturated $O$-glycosides from the reaction of 3,4,6-tri-O-acetyl-D-glucal and a wide range of alcohols in dichloromethane at room temperature. The experimental procedure is simple, and the products are obtained in high yields.

\section{Introduction}

2,3-Unsaturated $O$-glycosides play a substantial role in the synthesis of oligosaccharides [1], uronic acids [2], complex carbohydrates [3], and various natural products [4, 5]. Moreover, the unsaturated part of the sugar ring is amenable to easy functionalization such as hydrogenation, hydroxylation, epoxidation, and aminohydroxylation, which contribute to their diversities and complexities. One of the most common procedures to achieve 2,3-unsaturated $O$-glycosides is the acid-catalyzed allyl rearrangement of glucals, which was discovered by Ferrier and Prasad [6]. The Ferrier rearrangement is a reliable procedure for the formation of 2,3-unsaturated$O$-glycosides, which has known extensive development over decades [7]. This rearrangement typically occurs by treatment of glucals and alcohols with Lewis acids such as $\mathrm{BF}_{3} \cdot \mathrm{Et}_{2} \mathrm{O}$ [8], $\mathrm{FeCl}_{3}$ [9], Montmorillonite K-10 [10], $\mathrm{I}_{2}$ [11], $\mathrm{InCl}_{3}$ [12], $\mathrm{SiO}_{2}$ $\mathrm{Bi}(\mathrm{OTf})_{3}$ [13], $\mathrm{ZnCl}_{2} / \mathrm{Al}_{2} \mathrm{O}_{3}$ [14], or protic acids such as $\mathrm{H}_{2} \mathrm{SO}_{4}-\mathrm{SiO}_{2}$ [15], $\mathrm{H}_{3} \mathrm{PO}_{4}$ [16], $\mathrm{H}_{2} \mathrm{SO}_{4} / 4 \AA$ molecular sieves [17], $\mathrm{CF}_{3} \mathrm{SO}_{3} \mathrm{H}-\mathrm{SiO}_{2}$ [18], and (S)-camphorsulfonic acid [19]; $\mathrm{Er}(\mathrm{OTf})_{3}[20,21]$ as catalyst has also been reported. Although some of these methods have been used for the synthesis of 2,3unsaturated $O$-glycosides with good to high yields, the majority of them suffer at least from one of disadvantages, such as prolonged reaction times, low yields, harsh reaction conditions, difficulty in the preparation and moisture sensitivity of the catalysts, and high cost and toxicity of the reagents.
Therefore, there is a scope to develop an alternative method for the synthesis of 2,3-unsaturated $O$-glycosides.

Cyanuric chloride (TCT) is an inexpensive, easily available reagent of low toxicity and less corrosiveness than other similar reactants and has been widely used in organic reactions [22-24], but it has not been carefully studied as a catalyst in the synthesis of 2,3-unsaturated $O$-glycosides until now. In this paper, we wish to report a rapid and highly efficient method for the synthesis of 2,3-unsaturated $O$-glycosides in the presence of TCT at room temperature (Scheme 1).

\section{Experimental}

2.1. General. ${ }^{1} \mathrm{H}$ NMR and ${ }^{13} \mathrm{C}$ NMR spectra were determined on Bruker AV-400 spectrometer at room temperature using tetramethylsilane (TMS) as an internal standard, coupling constants $(J)$ were measured in $\mathrm{Hz}$; elemental analyses were performed by a Vario-III elemental analyzer; commercially available reagents were used throughout without further purification unless otherwise stated.

2.2. General Procedure for the Preparation of 3. To a solution of 3,4,6-tri-O-acetyl-D-glucal (272 mg, $1 \mathrm{mmol}$ ) in $\mathrm{CH}_{2} \mathrm{Cl}_{2}$ $(5 \mathrm{~mL})$ were added the corresponding alcohol $(1.2 \mathrm{mmol})$ and TCT (18 mg, $0.10 \mathrm{mmol})$. The mixture was stirred at room temperature for an appropriate time (Table 2). After completion of the reaction (TLC), the reaction mixture was treated 
<smiles>CC(=O)OC[C@H]1OC=C[C@H](OC(C)=O)[C@H]1OC(C)=O</smiles>

Scheme 1: Synthesis of 2,3-unsaturated O-glycosides.

with $10 \mathrm{~mL}$ water and extracted with $\mathrm{CH}_{2} \mathrm{Cl}_{2}(3 \times 10 \mathrm{~mL})$. The combined organics were dried over anhydrous $\mathrm{Na}_{2} \mathrm{SO}_{4}$. The solvent was removed under vacuum. All the products were purified by silica gel column chromatography (hexane/ethyl acetate $=9 / 1$ ). The structures of products were identified through comparison of these spectra data with those in the known literatures [8-19]. Spectral data for selected compounds are as follows.

2.3. Spectral Data of Some Selected Compounds. n-Butyl 4,6di- $O$-acetyl-2,3-dideoxy- $\alpha$-D-erythro-hex-2-enopyranoside (3c). ${ }^{1} \mathrm{H}$ NMR $\left(400 \mathrm{MHz}, \mathrm{CDCl}_{3}\right): \delta 5.80-5.65(\mathrm{~m}, 2 \mathrm{H}), 5.18$ $(\mathrm{dd}, J=1.2,9.6 \mathrm{~Hz}, 1 \mathrm{H}), 4.90(\mathrm{~s}, 1 \mathrm{H}), 4.06(\mathrm{dd}, J=5.6,12.4 \mathrm{~Hz}$, $1 \mathrm{H}), 4.2(\mathrm{dd}, J=2.4,12 \mathrm{~Hz}, 1 \mathrm{H}), 3.98-3.94(\mathrm{~m}, 1 \mathrm{H}), 3.66-3.35$ (m, 2H), 1.95 (s, 3H), $1.94(\mathrm{~s}, 3 \mathrm{H}), 1.47-1.23(\mathrm{~m}, 4 \mathrm{H}), 0.81(\mathrm{t}$, $3 \mathrm{H}) ;{ }^{13} \mathrm{C} \mathrm{NMR}\left(100 \mathrm{~Hz}, \mathrm{CDCl}_{3}\right): \delta 170.5,170.1,129.0,128.1$, 93.6, 68.9, 67.0, 65.6, 62.9, 31.8, 20.8, 20.7, 18.9, 13.8. Anal. Calcd. for $\mathrm{C}_{14} \mathrm{H}_{22} \mathrm{O}_{6}$ : C 58.73, H, 7.74. Found: C 58.65; H, 7.69.

Benzyl 4,6-di-O-acetyl-2,3-dideoxy- $\alpha$-D-erythro-hex-2enopyranoside (31). ${ }^{1} \mathrm{H}$ NMR (400 MHz, $\mathrm{CDCl}_{3}$ ): $\delta 7.33-7.25$ (m, 5H), 5.93-5.83 (m, 2H), $5.29(\mathrm{dd}, J=1.6,2.8 \mathrm{~Hz}, 1 \mathrm{H}), 5.12$ $(\mathrm{s}, 1 \mathrm{H}), 4.82(\mathrm{~d}, J=11.6 \mathrm{~Hz}, 1 \mathrm{H}), 4.64-4.55(\mathrm{~m}, 1 \mathrm{H}), 4.32-4.08$ $(\mathrm{m}, 3 \mathrm{H}), 2.07$ (s, 3H), $2.05(\mathrm{~s}, 3 \mathrm{H}) ;{ }^{13} \mathrm{C} \mathrm{NMR}\left(100 \mathrm{~Hz}, \mathrm{CDCl}_{3}\right)$ : $\delta 170.5,170.1,137.4,129.5,128.3,128.0,127.8,127.7,92.9,70.6$, 67.2, 64.9, 63.0, 20.8, 20.6. Anal. Calcd. for $\mathrm{C}_{17} \mathrm{H}_{20} \mathrm{O}_{6}$ : C 63.74, H, 6.29. Found: C 63.88; H, 6.20.

Cyclohex-2-enyl 4,6-di-O-acetyl-2,3-dideoxy- $\alpha$-D-erythro-hex-2-enopyranoside (3j). ${ }^{1} \mathrm{H} \mathrm{NMR}\left(400 \mathrm{MHz}, \mathrm{CDCl}_{3}\right): \delta$ 5.87-5.75 (m, 4H), $5.30(\mathrm{~d}, J=8.8 \mathrm{~Hz}, 1 \mathrm{H}), 5.20(\mathrm{~d}, J=18.0 \mathrm{~Hz}$, $1 \mathrm{H}), 4.27-4.14(\mathrm{~m}, 4 \mathrm{H}), 2.09$ (s, 3H), 2.08 (s, 3H), 2.03-1.93 (m, 3H), $1.84-1.70(\mathrm{~m}, 2 \mathrm{H}), 1.56(\mathrm{~m}, 1 \mathrm{H}) ;{ }^{13} \mathrm{C} \mathrm{NMR}(100 \mathrm{~Hz}$, $\left.\mathrm{CDCl}_{3}\right): \delta 170.7,170.3,131.6,128.8,128.6,128.4,128.3,93.8$, 72.9, 67.0, 65.6, 62.9, 29.9, 24.8, 21.2, 19.8. Anal. Calcd. for $\mathrm{C}_{15} \mathrm{H}_{24} \mathrm{O}_{6}$ : C 59.98, H, 8.05. Found: C 60.02; H, 8.02.

Pregnenolonyl 4,6-di-O-acetyl-2,3-dideoxy- $\alpha$-D-erythro-hex-2-enopyranoside (3o). ${ }^{1} \mathrm{H} \mathrm{NMR}\left(400 \mathrm{MHz}, \mathrm{CDCl}_{3}\right): \delta$ $5.86(\mathrm{~d}, J=10.0 \mathrm{~Hz}, 1 \mathrm{H}), 5.75(\mathrm{~d}, J=10.0 \mathrm{~Hz}, 1 \mathrm{H}), 5.31(\mathrm{~s}, 1 \mathrm{H})$, $5.24(\mathrm{~d}, J=10.0 \mathrm{~Hz}, 1 \mathrm{H}), 5.13(\mathrm{~s}, 1 \mathrm{H}), 4.20-3.55(\mathrm{~m}, 4 \mathrm{H}), 2.52(\mathrm{t}$, $J=8.0 \mathrm{~Hz}, 1 \mathrm{H}), 2.38-2.14(\mathrm{~m}, 3 \mathrm{H}), 2.11(\mathrm{~s}, 3 \mathrm{H}), 2.06(\mathrm{~s}, 3 \mathrm{H})$, $2.05(\mathrm{~s}, 3 \mathrm{H}), 2.02(\mathrm{~d}, J=9.5 \mathrm{~Hz}, 1 \mathrm{H}), 1.99-1.42(\mathrm{~m}, 11 \mathrm{H}), 1.23-$ $1.11(\mathrm{~m}, 2 \mathrm{H}), 1.06-0.96(\mathrm{~m}, 5 \mathrm{H}), 0.62(\mathrm{~s}, 3 \mathrm{H}) ;{ }^{13} \mathrm{C} \mathrm{NMR}$ $\left(100 \mathrm{~Hz}, \mathrm{CDCl}_{3}\right): \delta 208.9,170.8,170.3,140.5,128.7,128.2,121.3$, 93.0, 78.2, 67.0, 65.5, 63.7, 63.2, 56.4, 50.0, 44.1, 40.5, 38.3, 37.3, 36.2, 31.8, 31.7, 31.4, 27.9, 24.3, 22.8, 21.2, 21.0, 20.8, 19.5, 13.5 . Anal. Calcd. for $\mathrm{C}_{31} \mathrm{H}_{44} \mathrm{O}_{7}$ : C 70.43, H, 8.39. Found: C 70.29; H, 8.27.
TABLE 1: Reaction conditions optimisation for the synthesis of $\mathbf{3 a}$.

\begin{tabular}{lcccc}
\hline Entry & Catalyst/mmol & Solvent & Time/min & Yield/\% \\
\hline 1 & 0 & $\mathrm{CH}_{2} \mathrm{Cl}_{2}$ & 120 & Trace \\
2 & 0.05 & $\mathrm{CH}_{2} \mathrm{Cl}_{2}$ & 60 & 79 \\
3 & 0.10 & $\mathrm{CH}_{2} \mathrm{Cl}_{2}$ & 30 & 90 \\
4 & 0.15 & $\mathrm{CH}_{2} \mathrm{Cl}_{2}$ & 30 & 89 \\
5 & 0.20 & $\mathrm{CH}_{2} \mathrm{Cl}_{2}$ & 30 & 90 \\
6 & 0.10 & $\mathrm{CH}_{3} \mathrm{CN}$ & 30 & 82 \\
7 & 0.10 & $\mathrm{Acetone}$ & 30 & 80 \\
8 & 0.10 & THF & 30 & 69 \\
9 & 0.10 & Ethyl ether & 60 & 42 \\
\hline
\end{tabular}

\section{Results and Discussion}

In a typical reaction procedure, 2,3-unsaturated $O$-glycosides 3 were prepared, from the reaction of 3,4,6-tri-O-acetyl-Dglucal 1 and alcohols 2 in $\mathrm{CH}_{2} \mathrm{Cl}_{2}$ at room temperature in the presence of TCT as catalyst (Scheme 1). Since in this new kind of methodology, there is a great challenge to find new catalysts able to perform the reactions with high activities, we considered TCT as a potential promoter due to its good features for such a transformation. During our investigation, we firstly chose the reaction of 3,4,6-tri-O-acetyl-D-glucal $(1 \mathrm{mmol})$ and methanol $(1.2 \mathrm{mmol})$ as model reactants and examined the effect of the different amounts of TCT (Table 1). When above model reactants were conducted in $\mathrm{CH}_{2} \mathrm{Cl}_{2}$ $(5 \mathrm{~mL})$ in the presence of $0,0.05,0.10,0.15$, and $0.20 \mathrm{mmol}$ of TCT separately, the best result was obtained using $0.10 \mathrm{mmol}$ of catalyst (yield $=90 \%$ ). Using lower amounts of catalyst resulted in lower yields, while higher amounts of catalyst did not affect the reaction times and yields (Table 1, entries 25). In the absence of catalyst, the product was not formed (Table 1, entry 1). In order to evaluate the effect of the solvent, the reaction of 3,4,6-tri-O-acetyl-D-glucal and methanol in the presence of TCT was performed in various solvents such as $\mathrm{CH}_{2} \mathrm{Cl}_{2}, \mathrm{CH}_{3} \mathrm{CN}$, acetone, THF, and ethyl ether, in which the best result was obtained in $\mathrm{CH}_{2} \mathrm{Cl}_{2}$ (Table 1, entry 3 ); thus, we chose it as the solvent for all further reactions (Table 1 , entries 6-9).

Under the optimum conditions, a wide range of alcohols, including primary, secondary, and allylic alcohols, reacted with acetylated glucal according to Scheme 1 using $10 \mathrm{~mol} \%$ of TCT at room temperature to give the corresponding 2,3unsaturated $O$-glycosides in good to excellent yields and in very short reaction time with $\alpha$-anomer as a major product (Table 2).

Encouraged by these results, we next explored the scope of this methodology for the synthesis of pseudoglycals connected to various biologically important natural products (Table 2, entries 15-17). Under our catalytic conditions, pregnenolone, L-menthol, and borneol pseudoglycosides were obtained in $86 \%, 88 \%$, and $85 \%$ yields, respectively, with exclusive $\alpha$-anomeric selectivity.

The formation of products can be explained as follows: initially TCT reacts with the adventitious moisture to form 3 mol of $\mathrm{HCl}$ and cyanuric acid (removable by water washing) as a byproduct. The in situ generated $\mathrm{HCl}$ assists the 
TABle 2: Preparation of 2,3-unsaturated O-glycosides.

\begin{tabular}{|c|c|c|c|c|c|}
\hline Entry & Alcohols & Products & Time/min & Yield/\% & $\alpha / \beta^{\mathrm{a}}$ \\
\hline 1 & $\mathrm{MeOH}$ & & 30 & 90 & $7: 1$ \\
\hline 2 & $\mathrm{EtOH}$ & & 30 & 91 & $10: 1$ \\
\hline 3 & $\mathrm{O}$ & & 45 & 84 & $8: 1$ \\
\hline 4 & & & 30 & 89 & $8: 1$ \\
\hline 5 & & & 30 & 93 & $\alpha$ \\
\hline 6 & & & 45 & 89 & $\alpha$ \\
\hline 7 & & & 45 & 90 & $\alpha$ \\
\hline 8 & 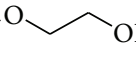 & & 30 & 88 & $8: 1$ \\
\hline 9 & & & 45 & 85 & $11: 1$ \\
\hline 10 & & & 45 & 94 & $11: 1$ \\
\hline & & $3 \mathbf{j}$ & & & \\
\hline
\end{tabular}


TABLe 2: Continued.

\begin{tabular}{|c|c|c|c|c|c|}
\hline Entry & Alcohols & Products & Time/min & Yield $/ \%$ & $\alpha / \beta^{\mathrm{a}}$ \\
\hline 11 & & & 45 & 91 & $10: 1$ \\
\hline 12 & & & 60 & 88 & $9: 1$ \\
\hline 13 & & & 60 & 87 & $9: 1$ \\
\hline 14 & & & 60 & 86 & $\alpha$ \\
\hline 15 & & & 60 & 86 & $\alpha$ \\
\hline 16 & & & 45 & 88 & $\alpha$ \\
\hline 17 & & & 45 & 85 & $\alpha$ \\
\hline
\end{tabular}

${ }^{\mathrm{a}}$ The $\alpha / \beta$ ratio was determined from the anomeric proton ratio in the ${ }^{1} \mathrm{H}$ NMR spectra. 


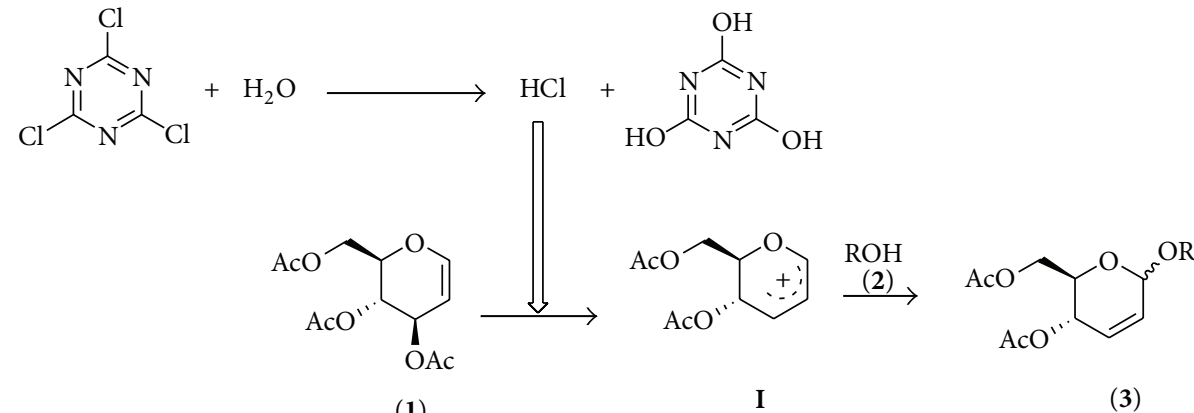

Scheme 2: Plausible mechanism for the formation of 2,3-unsaturated $O$-glycosides.

formation of the intermediate cyclic allylic oxocarbenium ion I from 3,4,6-tri-O-acetyl-D-glucal, which was originally proposed by Ferrier. Then, alcohol is added to the intermediate I in a quasiaxial fashion preferentially to provide the product 2,3-unsaturated $O$-glycosides 3 having major $\alpha$-selectivity as shown in Scheme 2.

\section{Conclusion}

In conclusion, we have developed a mild, eco-friendly approach for the synthesis of 2,3-unsaturated O-glycosides using a catalytic quantity of TCT. The main advantages of this method include good $\alpha$-selectivity, the use of inexpensive catalyst, and environmentally benign character. We believe that the methodology reported here is synthetically quite attractive and would spur on further interest toward the synthesis of complex glycosides.

\section{Conflict of Interests}

The authors have declared that no conflict of interest exists.

\section{Acknowledgment}

The authors are pleased to acknowledge the financial support from Xinxiang College.

\section{References}

[1] V. D. Bussolo, Y.-J. Kim, and D. Y. Gin, "Direct oxidative glycosylations with glycal donors," Journal of the American Chemical Society, vol. 120, no. 51, pp. 13515-13516, 1998.

[2] R. R. Schmidt and R. Angerbauer, "A short synthesis of racemic uronic acids and 2,3-anhydrouronic acids," Carbohydrate Research, vol. 89, no. 1, pp. 159-162, 1981.

[3] R. R. Schmidt and R. Angerbauer, "Simple de-novo synthesis of reactive pseudoglycals (hex-2-enopyranosides)-stereospecific $\alpha$-glycoside coupling," Angewandte Chemie, vol. 16, no. 11, pp. 783-784, 1977.

[4] A. G. Tolstikov and G. A. Tolstikov, "Glycals in enantiospecific synthesis," Russian Chemical Reviews, vol. 62, no. 6, pp. 579-601, 1993.
[5] B. Fraser-Reid, "Some progeny of 2,3-unsaturated sugars-they little resemble grandfather glucose: ten years later," Accounts of Chemical Research, vol. 18, no. 11, pp. 347-354, 1985.

[6] R. J. Ferrier and N. Prasad, "Unsaturated carbohydrates. Part IX. Synthesis of 2,3-dideoxy- $\alpha$-D-erythro-hex-2-enopyranosides from tri-O-acetyl-D-glucal," Journal of the Chemical Society $C$, vol. 1969, no. 4, pp. 570-575, 1969.

[7] P. Chen and P. Xiang, "Recent advances in the Ferrier-type rearrangement reactions and their applications in the complex bioactive molecules," Chinese Journal of Organic Chemistry, vol. 31, no. 8, pp. 1195-1201, 2011.

[8] E. Wieczorek and J. Thiem, "Preparation of modified glycosyl glycerol derivatives by glycal rearrangement," Carbohydrate Research, vol. 307, no. 3-4, pp. 263-270, 1998.

[9] R. D. Tilve, M. V. Alexander, A. C. Khandekar, S. D. Samant, and V. R. Kanetkar, "Synthesis of 2,3-unsaturated glycopyranosides by Ferrier rearrangement in $\mathrm{FeCl}_{3}$ based ionic liquid," Journal of Molecular Catalysis A, vol. 223, no. 1-2, pp. 237-240, 2004.

[10] K. Toshima, N. Miyamoto, G. Matsuo, M. Nakata, and S. Matsumura, "Environmentally compatible C-glycosidation of glycals using montmorillonite K-10," Chemical Communications, no. 11, pp. 1379-1380, 1996.

[11] M. Koreeda, T. A. Houston, B. K. Shull, E. Klemke, and R. J. Tuinman, "Iodine-catalyzed Ferrier reaction 1. A mild and highly versatile glycosylation of hydroxyl and phenolic groups," Synlett, vol. 1995, no. 1, pp. 90-92, 1995.

[12] B. S. Babu and K. K. Balasubramanian, "Indium trichloride catalyzed glycosidation. An expeditious synthesis of 2,3-unsaturated glycopyranosides," Tetrahedron Letters, vol. 41, no. 8, pp. 1271-1274, 2000.

[13] J. L. Babu, A. Khare, and Y. D. Vankar, "Bi(OTf) 3 and $\mathrm{SiO}_{2}$ $\mathrm{Bi}(\mathrm{OTf})_{3}$ as effective catalysts for the Ferrier rearrangement," Molecules, vol. 10, no. 8, pp. 884-892, 2005.

[14] B. K. Gorityala, R. Lorpitthaya, Y. Bai, and X.-W. Liu, “ $\mathrm{ZnCl}_{2}$ / alumina impregnation catalyzed Ferrier rearrangement: an expedient synthesis of pseudoglycosides," Tetrahedron, vol. 65, no. 29-30, pp. 5844-5848, 2009.

[15] J. F. Zhou, X. Chen, Q. B. Wang et al., " $\mathrm{H}_{2} \mathrm{SO}_{4}-\mathrm{SiO}_{2}$ : highly efficient and novel catalyst for the Ferrier-type glycosylation," Chinese Chemical Letters, vol. 21, no. 8, pp. 922-926, 2010.

[16] B. K. Gorityala, S. Cai, R. Lorpitthaya, J. Ma, K. K. Pasunooti, and X.-W. Liu, "A convenient synthesis of pseudoglycosides via a Ferrier-type rearrangement using metal-free $\mathrm{H}_{3} \mathrm{PO}_{4}$ catalyst," Tetrahedron Letters, vol. 50, no. 6, pp. 676-679, 2009.

[17] J. Zhou, B. Zhang, G. Yang et al., "A facile $\mathrm{H}_{2} \mathrm{SO}_{4} / 4$ A molecular sieves catalyzed synthesis of 2,3-unsaturated $O$-glycosides via 
Ferrier-type rearrangement," Synlett, vol. 2010, no. 6, pp. 893896, 2010.

[18] P. Chen and S. Wang, " $\mathrm{CF}_{3} \mathrm{SO}_{3} \mathrm{H}-\mathrm{SiO}_{2}$ as catalyst for Ferrier rearrangement: an efficient procedure for the synthesis of pseudoglycosides," Tetrahedron, vol. 69, no. 2, pp. 583-588, 2013.

[19] B. K. Gorityala, S. Cai, J. Ma, and X.-W. Liu, "(S)-Camphorsulfonic acid catalyzed highly stereoselective synthesis of pseudoglycosides," Bioorganic \& Medicinal Chemistry Letters, vol. 19, no. 11, pp. 3093-3095, 2009.

[20] A. Procopio, R. Dalpozzo, A. De Nino, M. Nardi, M. Oliverio, and B. Russo, "Er(OTf $)_{3}$ as a valuable catalyst in a short synthesis of $2^{\prime}, 3^{\prime}$-dideoxy pyranosyl nucleosides via Ferrier rearrangement," Synthesis, vol. 2006, no. 15, pp. 2608-2612, 2006.

[21] A. Procopio, R. Dalpozzo, A. De Nino et al., "A facile Er(OTf) $3_{3}^{-}$ catalyzed synthesis of 2,3-unsaturated $O$ - and S-glycosides," Carbohydrate Research, vol. 342, no. 14, pp. 2125-2131, 2007.

[22] G. V. M. Sharma, J. J. Reddy, P. S. Lakshmi, and P. R. Krishna, "A versatile and practical synthesis of bis(indolyl)methanes/ bis(indolyl) glycoconjugates catalyzed by trichloro-1,3,5-triazine," Tetrahedron Letters, vol. 45, no. 41, pp. 7729-7732, 2004.

[23] L. Wu, X. Yang, X. Wang, and F. Yan, "Cyanuric chloride-catalyzed synthesis of N-sulfonyl imines," Journal of Sulfur Chemistry, vol. 31, no. 6, pp. 509-513, 2010.

[24] M. A. Bigdeli, M. M. Heravi, and G. H. Mahdavinia, "Wet cyanuric chloride catalyzed simple and efficient synthesis of 14-aryl or alkyl-14-H-dibenzo[a,j]xanthenes," Catalysis Communications, vol. 8, no. 11, pp. 1595-1598, 2007. 

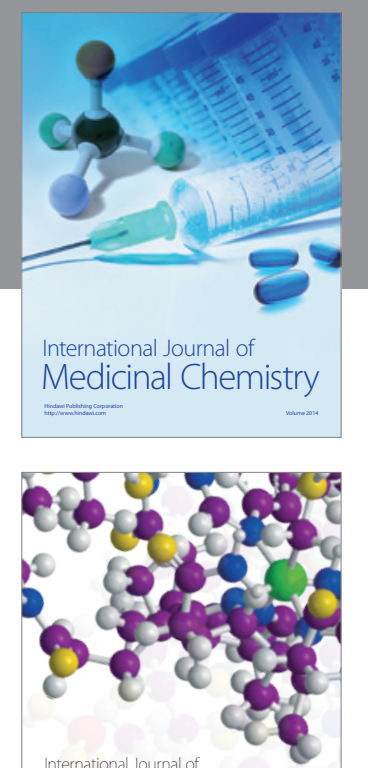

\section{Carbohydrate} Chemistry

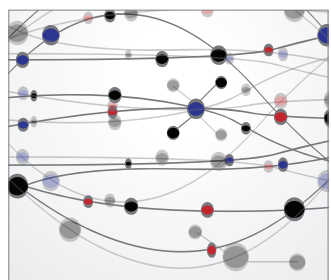

The Scientific World Journal
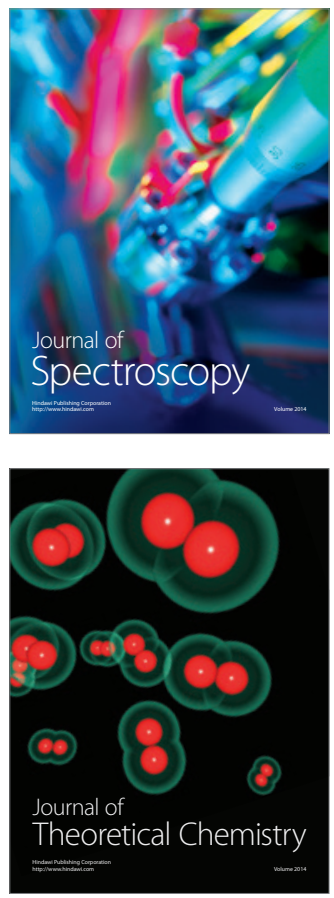
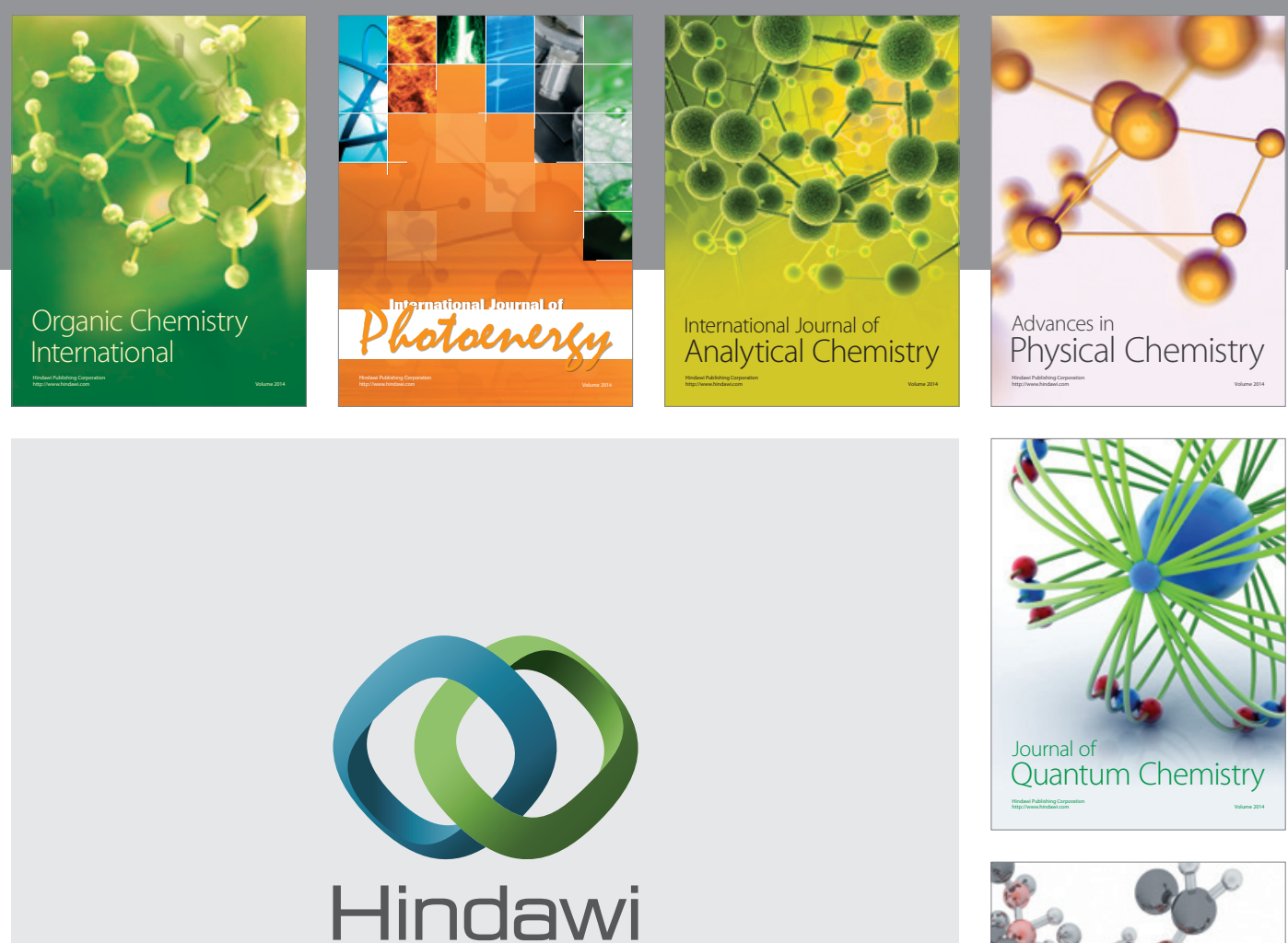

Submit your manuscripts at

http://www.hindawi.com

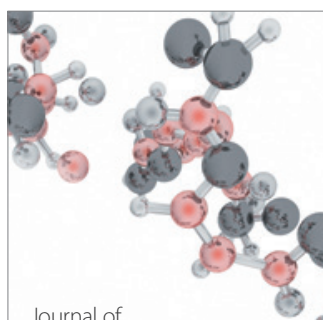

Analytical Methods

in Chemistry

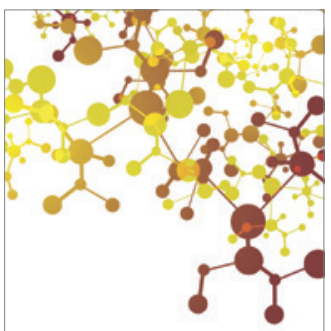

Journal of

Applied Chemistry

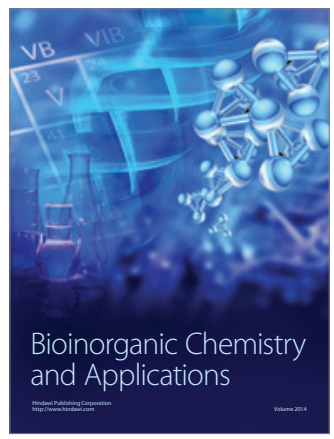

Inorganic Chemistry
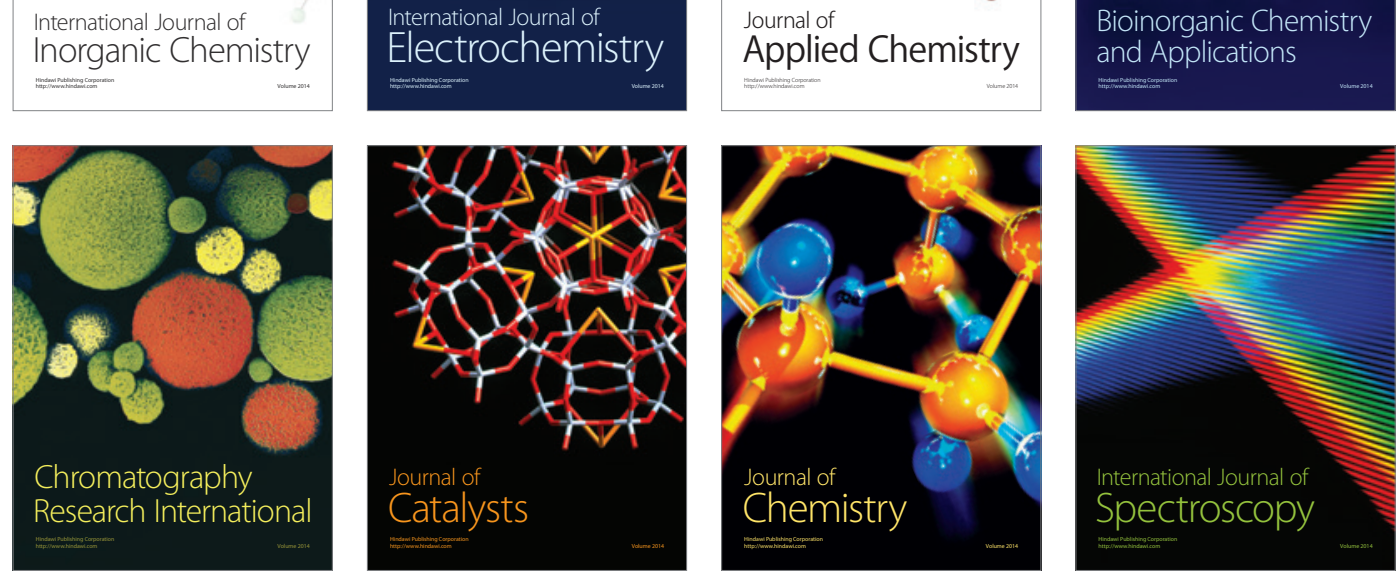